\title{
aImplementasi Logika Fuzzy dalam Memprediksi Tingkat Kelulusan Tes Seleksi CPNS dengan Menggunakan Metode Tsukamoto
}

\author{
Romantika Tambunan ${ }^{1 *}$, Murni Marbun ${ }^{2}$ \\ 1,2 STMIK Pelita Nusantara \\ Jl. Iskandar Muda No. 1 Medan 20154 Indonesia \\ Corresponding author's e-mail: romantikatambunan@gmail.com
}

\begin{abstract}
Abstrak-Para pelamar yang mengikuti seleksi penerimaan Calon Pegawai Negeri Sipil (CPNS) harus melewati tahap-tahap yang harus ditempuh yang dapat menentukan pada tingkat kelulusan. Kriteria memprediksi kelulusan tes seleksi CPNS yang digunakan Seleksi Kompetensi Dasar (SKD) yang terdiri dari Tes Karakteristik Pribadi (TKP), Tes Intelegensi Umum (TIU), Tes Wawasan Kebangsaan (TWK), Seleksi Kompetensi Bagian (SKB) yang terdiri dari computer assited Test (CAT) dan Wawancara, dan jumlah kuota yang diterima. Penelitian ini adalah Implementasi Logika Fuzzy Tsukamoto dalam Memprediksi Tingkat Kelulusan Tes Seleksi CPNS. Sistem memprediksi kelulusan tes seleksi CPNS dibangun dengan menggunakan bahasa pemograman PHP berbasis Web. Pengelolaan data menggunakan MySQL. Hasil defuzzyfikasi (Z) secara keseluruhan pada sistem memprediksi tingkat kelulusan CPNS $=61,950223979=62$.
\end{abstract}

Kata kunci: kriteria prediksi, prediksi, logika fuzzy, Tsukamoto

Abstract - Applicants who take part in the selection of Candidates for Civil Servant Candidates (CPNS) must pass through the steps that must be taken which can determine the graduation rate. The criteria for predicting the passing of the CPNS selection test are used by the Basic Competency Selection (SKD) which consists of a Personal Characteristic Test (TKP), General Intelligence Test (TIU), National Insight Test (TWK), Competency Selection Section (SKB) which consists of a computer assisted test (CAT) and interviews, and the number of quotas received. This research is the implementation of Fuzzy Tsukamoto Logic in Predicting the Passing Rate of the CPNS Selection Test. The system for predicting the passing of the CPNS selection test was built using the Web-based PHP programming language. Data management using MySQL database. The overall defuzzyfication $(Z)$ result in the system predicts the passing rate of CPNS $=61.950223979=62$.

Keywords: prediction criteria, prediction, fuzzy logic, Tsukamoto

\section{Pendahuluan}

Para pelamar memiliki kesulitan dalam memprediksi nilai kelulusan pada setiap tahap yang harus dilaluinya. Saat ini dengan tingginya antusias masyarakat indonesia dalam mengikuti Tes seleksi penerimaan Calon Pegawai Negeri Sipil (CPNS) maka sangat dibutuhkan sebuah sistem yang berkualitas dalam menentukan tingkat kelulusan calon pegawai negeri sipil (CPNS). Oleh karena itu diperlukan suatu sistem dalam memprediksi tingkat kelulusan pada setiap tahapan karena akan memberikan kemudahan bagi para pelamar untuk memperkirakan tingkat kelulusan dengan baik. Pada saat ini belum ada sistem yang dapat memprediksi tingkat kelulusan CPNS Sehingga menyebabkan peserta tidak memiliki persiapan dan teknik yang harus dilakukan agar lulus CPNS. Perhitungan nilai pada tahap awal berdasarkan passing grade yang sudah ditentukan, setelah diperoleh hasil dari perhitungan akan dilakukan kembali perankingan terhadap nilai untuk mengambil nilai teratas sesuai dengan banyaknya kuota yang dibutukan untuk dapat melanjut ke tahap selanjutnya. Jumlah kuota yang diterima dengan banyaknya saingan yang mengambil formasi yang sama tidak sebanding sehingga peluang kelulusan semakin rendah. Oleh karena itu dibutuhkan suatu metode Logika Fuzzy untuk memprediksi nilai kelulusan tes seleksi CPNS.

. Logika Fuzzy adalah suatu cara yang tepat untuk memetakan suatu ruang input dalam suatu ruang output dan memiliki nilai yang berlanjut [1]. Teori himpunan Fuzzy, peranan derajat keanggotaan sebagai penentu keberadaan elemen dalam suatu himpunan sangatlah penting. Nilai keanggotaan atau derajat keanggotaan menjadi ciri utama dalam penalaran dengan Logika Fuzzy. Penerapan Logika Fuzzy adalah cara yang tepat untuk memetakan suatu ruang input dalam suatu ruang output dan memiliki nilai yang berlanjut. Logika yang menggunakan konsep sifat kesamaran dengan banyak kebenaran yang dinyatakan dalam bilangan real dalam selang $[0,1]$. Dalam Logika Fuzzy pengambilan keputusan dilakukan dengan sistem inferensi yang disebut dengan sistem inferensi fuzzy yang merupakan proses pengambilan kesimpulan berdasarkan penalaran Logika Fuzzy. Sistem Inferensi Fuzzy dapat dilakukan dengan menggunakan beberapa metode yaitu metode mamdani, metode tsukamoto, dan metode sugeno [2]. Dalam metode Tsukamoto, setiap aturan direpresentasikan menggunakan himpunan fuzzy, dengan fungsi keanggotaan yang monoton. Untuk menentukan nilai output 
crisp/hasil yang tegas $(Z)$ dicari dengan cara mengubah input (berupa himpunan fuzzy yang diperoleh dari komposisi aturan-aturan fuzzy) menjadi suatu bilangan pada domain himpunan fuzzy tersebut. Cara ini disebut dengan metode defuzzifikasi (penegasan). Metode defuzzifikasi yang digunakan dalam metode Tsukamotoadalah metode defuzzifikasi rata-rata terpusat (Center Average Defuzzyfier) [3]. Pada penelitian penerapan Metode Fuzzy Tsukamoto dapat membantu kinerja HRD dalam melaksanakan seleksi karyawan baru pada suatu perusahaan dan berdasarkan uji coba yang dilakukan penerapan fuzzy tsukamoto memiliki tingkat validitas yang cukup tinggi yaitu $86,67 \%$ sehingga mampu memberikan hasil penilaian yang baik [4].

Penelitian analisa perbandingan logic fuzzy metode tsukamoto, sugeno, dan mamdani (studi kasus : prediksi jumlah pendaftar mahasiswa baru Fakultas Sains Dan Teknologi Universitas Islam Negeri Sunan Gunung Djati Bandung) menjelaskan Fuzzy Inference System Tsukamoto 1. Saat proses evaluasi aturan dalam mesin inferensi, metode fuzzy Tsukamoto menggunakan fungsi implikasi MIN untuk mendapatkan nilai $\alpha$-predikat tiap-tiap rule $(\alpha 1, \alpha 2, \alpha 3, \ldots \ldots$ n). Masing-masing nilai $\alpha$ - predikat digunakan untuk menghitung hasil inferensi secara tegas (crisp) masingmasing rule (z1, z2, z3,... zn) [5]. Penelitian Analisis Komparasi Metode Tsukamoto dan Sugeno dalam Prediksi Jumlah Siswa Baru menjelaskan . Dalam teori logika fuzzy dikenal suatu konsep sistem fuzzy yang digunakan dalam proses prediksi dan pada umumnya terdiri atas empat tahap, yaitu fuzzifikasi (pengubahan bilangan tegas ke dalam bentuk bilangan fuzzy), pembentukan rule base (basis aturan fuzzy), sistem inferensi/penalaran fuzzy, dan defuzzifikasi (pengubahan bilangan fuzzy hasil dari proses inferensi fuzzy ke dalam bentuk bilangan tegas) [6].

\section{Tinjauan Pustaka}

\subsection{Logika Fuzzy}

Dasar logika fuzzy adalah teori himpunan fuzzy [7]. Pada teori himpunan fuzzy, peranan derajat keanggotaan sebagai penentu keberadaan elemen dalam suatu himpunan sangatlah penting. Nilai keanggotaan atau derajat keanggotaan atau membership function menjadi ciri utama dari penalaran dengan logika fuzzy. Komposisi Aturan Fuzzy, apabila sistem terdiri dari beberapa aturan, maka dilakukan inferensi yang diperoleh dari kumpulan dan korelasi aturan-aturan [8]. Ada tiga metode yang digunakan dalam melakukan inferensi sistem fuzzy logic, yaitu metode mamdani (Metode Max-Min), metode sugeno, metode penegasan (Defuzziikasi) dan metode tsukamoto .

\subsection{Metode Tsukamoto}

Metode Tsukamoto, setiap konsekuen pada aturan yang berbentuk IF-THEN harus direpresentasikan dengan suatu himpunan fuzzy dengan fungsi keanggotaan yang monoton [9]. Sebagai hasilnya, output hasil inferensi dari tiap-tiap aturan diberikan secara tegas (crisp) berdasarkan $\alpha$-predikat (fire strength). Hasil akhirnya diperoleh dengan menggunakan rata-rata terbobot. Misalkan ada 2 variabel input, Var-1 (x) dan Var2 (y), serta 1 variabel output, Var-3(z), dimana Var-1 terbagi atas 2 himpunan yaitu A1 dan A2 terbagi atas 2 himpunan B1 dan B2, Var-3 juga terbagi atas 2 himpunan yaitu $\mathrm{C} 1$ dan $\mathrm{C} 2$. Ada2 aturan yang digunakan, yaitu [10]:

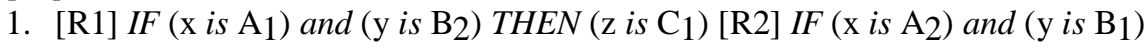

2. THEN ( $\mathrm{z}$ is $\left.\mathrm{C}_{2}\right)$ Alur inferensi seperti untuk mendapatkan satu nilai crisp $\mathrm{z}$.

\section{Metode Penelitian}

Tahap dalam penelitian adalah sebagai berikut:

a. Indentifikasi Masalah

Pada proses identifikasi masalah, mengadakan survey pendahuluan dan menentukan objek penelitian yang berkaitan dengan topik permasalahan penelitian.

b. Pengumpulan Data

Dalam pelaksanaan penelitian ini dibutuhkan dua jenis data yaitu data primer, mengumpulkannya secara langsung, dan Data sekunder, diperoleh atau dikumpulkan dari berbagai sumber

c. Penerapan Metode

Penerapan Metode Tsukamoto, pada tahapan ini setelah peneliti mengumpulkan data dan informasi, maka peneliti menerapkan metode Tsukmaoto dalam penelitian memprediksi tingkat kelulusan tes seleksi CPNS dimana setiap konsekuen variabel kelulusan pada aturan berbentuk IF-THEN harus direpresentasikan dengan himpunan Fuzzy yang fungsi keanggotaannya bernilai [0,1] sehingga menggunakan operasi himpunan fuzzy irisan(intersection), gabungan (union), dan komplemen (complement).

d. Analisa dan Perancangan

Analisa dan Perancangan, pada tahapan ini bagaimana menganalisa sistem yang dibangun meliputi analisis pengguna sistem, analisis kebutuhan sistem dan analisis variabel fuzzy yang digunakan oleh sistem. Tahap 
Perancangan adalah merancang atau mendesain suatu sistem agar mendapatkan hasil yang maksimal, tahap perancangan sistem dibahas perancangan fungsi-fungsi program yang digunakan, perancangan Unified Modelling Language (UML), perancangan flowchart, perancangan database dan perancangan antarmuka (user interface) serta pengguna harus menentukan pilihan kriteria dikehendaki dari setiap variabel spesifikasi yang disajikan pada sistem.

e. Impelementasi Sistem

Implementasi sistem, tahapan ini merupakan suatu langkah yang ditunjukkan untuk diimplementasi. Dan yang menjadi output dalam penelitian ini yaitu sebuah sistem yang dibangun menggunakan Bahasa Pemograman PHP dan HTML dan Database Mysql.

f. Evaluasi sistem, tahapan ini menunjukan apakah sistem yang telah dibuat telah sesuai dengan yang diharapkan

\section{Hasil dan Pembahasan}

Pembentukan himpunan fuzzy digunakan untuk mendefenisikan nilai-nilai masukan tegas. Variabel SKD (TKP, TIU dan TWK) dan SKB (CAT dan Wawanacara) sebagai variabel masukan, variabel Kuota sebagai variabel keluaran. Semesta pembicara pada penelitian ini diperoleh dengan melihat data terendah dan tertinggi dari data variabel masukan dan keluaran.

Tabel 1. Semesta pembicara untuk setiap variabel fuzzy

\begin{tabular}{|l|l|l|}
\hline Fungsi & Nama Variabel & Semesta pembicara \\
\hline \multirow{4}{*}{ Input } & SKD (TKP) & {$[0,175]$} \\
\cline { 2 - 3 } & SKD (TIU) & {$[0,175]$} \\
\cline { 2 - 3 } & SKD (TWK) & {$[0,150]$} \\
\cline { 2 - 3 } & SKB (CAT) & {$[0,500]$} \\
\cline { 2 - 3 } & SKB (Wawancara) & {$[0,100]$} \\
\hline Output & Kuota & {$[0,100]$} \\
\hline
\end{tabular}

Klasifikasi skor himpunan fuzzy untuk semua variabel adalah 0 sampai dengan 500. Berikut adalah tabel klasifikasi skor himpunan fuzzy untuk semua variabel.

Tabel 2. Himpunan Fuzzy

\begin{tabular}{|c|c|c|c|}
\hline \multicolumn{2}{|c|}{ Variabel } & Derajat Keanggotaan & Domain \\
\hline \multirow[t]{5}{*}{ Input } & SKD (TKP) & $\begin{array}{l}\text { 1. Tinggi } \\
\text { 2. Cukup Tinggi } \\
\text { 3. Kurang Tinggi }\end{array}$ & $\begin{array}{l}\text { 1. }[145,175] \\
\text { 2. }[110,150] \\
\text { 3. }[0,126]\end{array}$ \\
\hline & SKD (TIU) & $\begin{array}{l}\text { 1. Tinggi } \\
\text { 2. Cukup Tinggi } \\
\text { 3. Kurang Tinggi }\end{array}$ & $\begin{array}{l}\text { 1. }[120,175] \\
\text { 2. }[75,130] \\
\text { 3. }[0,85]\end{array}$ \\
\hline & SKD (TWK) & $\begin{array}{l}\text { 1. Tinggi } \\
\text { 2. Cukup Tinggi } \\
\text { 3. Kurang Tinggi }\end{array}$ & $\begin{array}{l}\text { 1. }[100,150] \\
\text { 2. }[50,110] \\
\text { 3. }[0,65]\end{array}$ \\
\hline & SKB (CAT) & $\begin{array}{l}\text { 1. Tinggi } \\
\text { 2. Cukup Tinggi } \\
\text { 3. Kurang Tinggi }\end{array}$ & $\begin{array}{l}\text { 1. }[340,500] \\
\text { 2. }[240,350] \\
\text { 3. }[0,250]\end{array}$ \\
\hline & SKB(Wawancara) & $\begin{array}{l}\text { 1. Bagus } \\
\text { 2. Cukup Bagus } \\
\text { 3. Kurang Bagus }\end{array}$ & $\begin{array}{l}\text { 1. }[60,100] \\
\text { 2. }[40,70] \\
\text { 3. }[0,50]\end{array}$ \\
\hline Output & Kuota & $\begin{array}{l}\text { 1. Memenuhi } \\
\text { 2. Tidak Memenuhi }\end{array}$ & $\begin{array}{l}\text { 1. }[60,100] \\
\text { 2. }[0,59]\end{array}$ \\
\hline
\end{tabular}

Fungsi Keanggotaan dengan Variabel SKD:

$$
\begin{aligned}
& \text { 1. } \mu_{\text {TKPKurangTinggi }}[\mathrm{x}]\left\{\begin{array}{cc}
1, & x \leq 0 \\
(126-x) /(126-0), 0 \leq x \geq 126 & x \geq 126
\end{array}\right. \\
& 0, \quad x \leq 110 \text { atau } x \geq 150 \\
& \text { 2. } \mu_{\text {TKPCukupTinggi }[\mathrm{x}]}\left(\begin{array}{c}
(x-110) /(130-110), 110 \leq x \geq 130 \\
(150-x) /(150) 130), 130 \leq x \geq 150
\end{array}\right. \\
& \text { 3. } \mu_{\text {TKPSangatTinggi }}[\mathrm{x}]\left\{\begin{array}{cc}
0, & x \leq 145 \\
(x-145) /(175-145), & 145 \leq x \geq 175 \\
1, & x \geq 175
\end{array}\right.
\end{aligned}
$$


Fungsi Keanggotaan dengan Variabel SKD:

1. $\mu_{\text {TIUKurangTingi }}[\mathrm{x}]\left\{\begin{array}{cc}1, & x \leq 0 \\ (85-x) /(85-0), & 0 \leq x \geq 85 \\ 0, & x \geq 85\end{array}\right.$

2. $\mu_{\text {TIUCukupTinggi }}[\mathrm{x}]\left\{\begin{array}{c}0, \quad x \leq 75 \text { atau } x \geq 130 \\ (x-75) /(95-75), 75 \leq x \geq 95 \\ (130-x) /(130-95), 95 \leq x \geq 130\end{array}\right.$

3. $\mu_{\text {TIUSangatTinggi }[\mathrm{x}]}\left\{\begin{array}{cc}0, & x \leq 120 \\ (x-120) /(175-120), & 120 \leq x \geq 175 \\ 1, & x \geq 175\end{array}\right.$

Fungsi Keanggotaan dengan Variabel SKD:

1. $\mu_{\text {TWKKurangTinggi }}[\mathrm{x}]\left\{\begin{array}{cc}1, & x \leq 0 \\ (65-x) /(65-0), & 0 \leq x \geq 65 \\ 0, & x \geq 65\end{array}\right.$

2. $\mu_{\text {TWKCukupTinggi }}[\mathrm{x}]\left\{\begin{array}{c}0, \quad x \leq 50 \text { atau } x \geq 110 \\ (x-50) /(85-50), 50 \leq x \geq 85 \\ (110-x) /(110-85), 85 \leq x \geq 110\end{array}\right.$

3. $\mu_{\text {TWKSangatTinggi }}[\mathrm{x}]\left\{\begin{array}{cc}0, & x \leq 100 \\ (x-100) /(150-100), & 100 \leq x \geq 150 \\ 1, & x=150\end{array}\right.$

Fungsi defuzzyfikasi adalah untuk mengolah output fuzzy yang diperoleh dari mesin inferensi menjadi nilai tegas dengan menggunakan fungsi keanggotaan yang sesuai dengan fuzzyfikasi yang telah dilakukan . hasil output diperoleh dari hasil (Z) rata-rata pembobotan (Mean).

Tabel 3. Hasil Prediksi Kelulusan Berdasarkan Kuota

\begin{tabular}{|c|c|c|c|}
\hline \multicolumn{3}{|c|}{ Hasil Prediksi Kelulusan Berdasar kan Kuota } & \multirow{2}{*}{ Prediksi } \\
\cline { 1 - 3 } No & Nama & Total Nilai & \\
\hline 1 & Rudi & 68,48 & Lulus \\
\hline 2 & Robert & 54,82 & Tdk Lulus \\
\hline 3 & Putri & 79,07 & Lulus \\
\hline 4 & Andika & 58,86 & Tdk Lulus \\
\hline 5 & Gilang & 58,76 & Tdk Lulus \\
\hline 6 & Dewi & 48,88 & Tdk Lulus \\
\hline
\end{tabular}

Perhitungan Nilai SKB, Nilai maksimal SKB 500, skala nilai maksimal 100, Gilang 300/500 =0,60 $* 100=$ 60 , Robert $350 / 500=0,75 * 100=75$. Salah satu seleksi yang dilaksanakan pada tes seleksi CPNS untuk mendapatkan data pelengkap teknik pengumpulan data, dan menguji hasil pengumpulan data yang berkaitan tentang jabatan/instansi yang sedang dilamar.

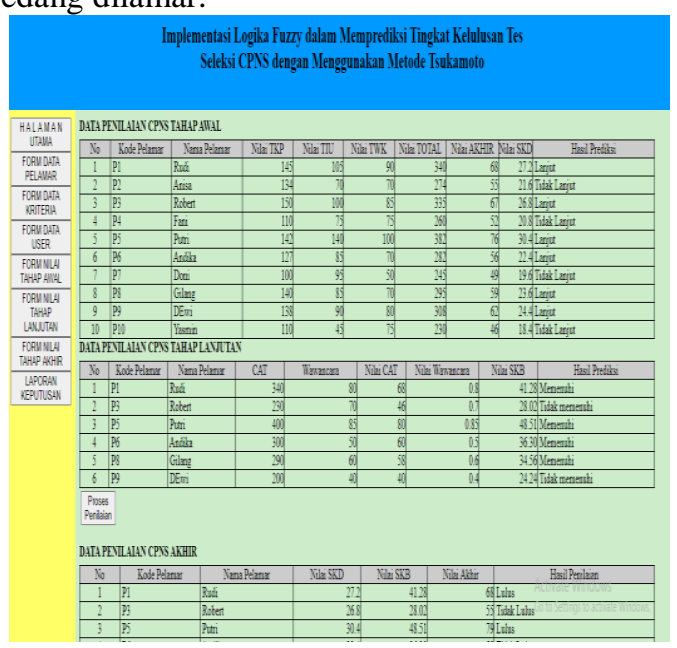

Gambar 1. Implementasi Logika Fuzzy dalam Memprediksi Tingkat Kelulusan

\section{Kesimpulan}


Kesimpulan dari penelitian :

1. Pada himpunan fuzzy yang bersangkutan yang hasilnya disebut $\alpha$, dan melakukan defuzzyfikasi dengan mengubah nilai keluaran fuzzy menjadi nilai keluaran tegas, dari hasil penerapan metode Logika Fuzzy Tsukamoto dari 10 pelamar yang di uji terdapat 2 pelamar yang akan lulus.

2. Sistem ini dibangun berbasis web dengan implementasi sistem terdiri dari form login, form halaman utama,form data pelamar, form data kriteria,form user, form nilai tahap awal, form nilai tahap lanjutan, form data akhir, dan form laporan keputusan.

\section{Daftar Pustaka}

[1] A. A. Caraka, "Implementasi Logika Fuzzy Metode Tsukamoto," pp. 1-11, 2010.

[2] M. D. Irawan and H. Herviana, "Implementasi Logika Fuzzy Dalam Menentukan Jurusan Bagi Siswa Baru Sekolah

Menengah Kejuruan (Smk) Negeri 1 Air Putih,” J. Teknol. Inf., vol. 2, no. 2, p. 129, 2019, doi: 10.36294/jurti.v2i2.427.

[3] N. Novita, "Metode Fuzzy Tsukamoto Untuk Menentukan Beasiswa," J. Penelit. Tek. Inform. Vol. 1 Nomor 1, Oktober 2016, vol. 1, pp. 51-54, 2016, doi: 2541-2019.

[4] M. Irfan, L. P. Ayuningtias, and J. Jumadi, "Analisa Perbandingan Logic Fuzzy Metode Tsukamoto, Sugeno, Dan Mamdani ( Studi Kasus : Prediksi Jumlah Pendaftar Mahasiswa Baru Fakultas Sains Dan Teknologi Uin Sunan Gunung Djati Bandung)," J. Tek. Inform., vol. 10, no. 1, pp. 9-16, 2018, doi: 10.15408/jti.v10i1.6810.

[5] R. T. Waruwu and A. Sindar, "SISTEM PAKAR MENENTUKAN JENIS GANGGUAN PERKEMBANGAN ANAK MENGGUNAKAN METODE CERTAINTY FACTOR,” vol. 2, no. 2, pp. 35-41, 2019.

[6] R. A. Kristian and I. Wahyuni, "Penentuan Topik Judul Tugas Akhir Mahasiswa di STMIK Asia Malang Menggunakan Fuzzy Inference System Tsukamoto," J. Ilm. Teknol. Inf. STMIK ASIA Malang, vol. 12, no. 01, pp. 33-47, 2018.

[7] A. Sanjaya and R. Ningsih, "Sistem Pendukung Keputusan Penentuan Calon Penerima Beasiswa Menggunakan Metode Fuzzy Database Model Tahani," Simetris J. Tek. Mesin, Elektro dan Ilmu Komput., vol. 7, no. 2, p. 449, 2016.

[8] M. F. J. Andri Saputra, "Sistem Pendukung Keputusan Pemilihan Penerima Bantuan Sosial Menggunakan Metode Fuzzy," Techno.COM, vol. 15, no. 1, pp. 32-42, 2016.

[9] Nurul Putri Utami, Hasanul Fahmi, and Anita Sindar, "Spk Penentuan Pemberian Pinjaman Kepada Anggota Bumdes Dengan Metode Simple Additive Weighting," SINTECH (Science Inf. Technol. J., vol. 2, no. 2, pp. 124-130, 2019.

[10] A. S. RM. Sinaga, "Binary Image Object Identification Using Fuzzy Logic and Labeling Breadh-First," Journal of Telematics and Informatics, vol. 6, no. 4, 2018. 